\section{Me scientist, you chimpanzee}

\author{
John C. Marshall
}

Ape Language: From Conditioned Response to Symbol. By E. Sue SavageRumbaugh. Columbia University Press/ Oxford University Press: 1986. Pp.433. $\$ 40, £ 30$.

IF I want to communicate effectively with members of a culture radically different from my own, there are two basic options open to me: either I learn their language or they learn mine. When the representatives of a different culture are also members of a different species, exactly the same options arise. Saint Francis (and later Karl von Frisch, Konrad Lorenz and Nico Tinbergen) chose the first route; Sue Savage-Rumbaugh (and earlier Beatrice and Allen Gardner, and David Premack) opted for the second. For sociologists, the fact that Europeans were prepared to adapt themselves to the world of the animals they studied, whilst Anglophones insist that the animals try to do it our way, may point a moral. For the rest of us, the continuing saga of the chimpanzee's ability to communicate in a human-like fashion shows no sign of losing its fascination.

Savage-Rumbaugh places her own contribution to the debate firmly within a neodarwinian context. The great apes are our closest living relatives: "....amino acid sequencing, immunological, and electrophoretic methods of protein comparison between man and chimpanzee all indicate that the average human polypeptide is more than 99 per cent identical to its chimpanzee counterpart". Yet despite this biochemical similarity - "comparable with that found among sibling species who are virtually identical in terms of morphology" - taxonomists continue to place man and chimpanzee in different families. That we should think of ourselves as being so very different from the great apes when they "share our biological heritage to a remarkable degree" seems somewhat perverse to SavageRumbaugh. The distinction, she writes, "has no biological basis, but appears to be derived instead from a singular behavioral distinction - the ability of man to speak". This argument is deeply puzzling, both in its equation of biology with the constitution of polypeptides, and in its implication that human language does not rest upon specific biological foundations. It is as if one were to argue that a Picasso and a Matisse must be highly similar because, when the paintings were ground up and centrifuged, they had a near identical spectrum of pigment types. Nonetheless, the evidence of genotypic similarity suggests to Savage-Rumbaugh that the phenotypic uniqueness of man has been greatly exaggerated. What better way, then, to demonstrate behavioural similarity than to show that the chimpanzee can, in an appropriate environment, acquire at least the rudiments of language skills as they are manifest in all normal human children?

The general drift of such a research programme has been familiar since the earliest days of biological classification. Linnaeus had placed the orang-utang in the human genus, albeit as a species separate from man; and Buffon claimed that the orang-utang was not a man solely because it could not talk. Lord Monboddo, the eighteenth-century Scottish linguist and eccentric, was unconvinced that the orang had been given a fair opportunity to demonstrate its prowess, and he proposed

"As with watching a circus horse walk on its hind legs, I could not escape the feeling that a species ill-adapted to symbolic communication was struggling with an unnatural task."

a simple solution: we should patiently teach an orang-utang to speak. If the animal could learn a language then it was indeed a primitive man. Some 200 years later, the chimpanzee has been substituted for the orang, the research programme has been carried out, and we now know that the answer is nowhere near as simple as Monboddo hoped.

In Ape Language, Savage-Rumbaugh makes no attempt to show that her young male chimpanzees, Sherman and Austin, can acquire even a simplified syntax. With the exception of the Gardners, no serious student of ape language now seems convinced that the chimpanzee can make productive use of a system in which People tickle chimpanzees means (roughly) the same as Chimpanzees are tickled by people, has a different meaning from Chimpanzees tickle people, and in which People by tickled are chimpanzees doesn't mean very much at all. But a language consists (minimally) of a syntax and a vocabulary. And for Savage-Rumbaugh the dominant question has become: can a chimpanzee demonstrate an appropriate, symbolic use of vocabulary items to communicate information to a human trainer or to a conspecific animal?

The question goes considerably beyond the well-known facts of natural animal signals, and of arbitrary response conditioning. If, severely provoked, I turn red and snarl, a conspecific may back away, but my expression is not the name of my emotional state; likewise, if properly conditioned, I raise my right hand each time the experimenter shows me a yellow circle, my gesture is not the name of the visual stimulus I was presented with. What evidence, then, would we require of a chimpanzee (or a human child) before we were prepared to concede that the use of a particular overt sign had symbolic significance, that it, in some sense, 'stood for' the concept of, say, banana?

The two most impressive demonstrations of symbolic communication that Savage-Rumbaugh reports are these. Austin sees on a television screen a tray of different foods; the screen is too small for him to point and indicate which food he wants. Austin goes to a computer console, and by pressing a key he lights up an arbitrary geometrical shape from a selection of such shapes that (in previous training sessions) had been associated with different foods. Sherman observes this sign, goes to the next room, wherein is found the real food tray. From this tray, he selects the correct food (having, like Austin, been previously trained in the relevant associations) and brings it back to Austin to eat. Both chimpanzees (eventually) became remarkably skilled in this game. Second demonstration: Sherman observes a tray of objects. He then goes to the keyboard and lights up a sign corresponding to one of them. The sign is transmitted by projectors to the trainer, who cannot see the chimpanzee. Sherman then returns to the tray, selects the object whose sign he pressed and gives that object to the trainer. Again, both chimpanzees (eventually) became highly adept.

Savage-Rumbaugh interprets the first experiment as the chimpanzee requesting that a particular food be brought, the second as announcing that a particular object will be brought. Exactly how pleased John (How To Do Things With Words) Austin would have been with Austin's performance, we can leave other philosophers to decide. For the moment, these demonstrations remain the best evidence we have for the deployment of an arbitrary symbolic code by any nonhuman primate. The 433 pages of Ape Language do, however, amply document just how difficult it was to get the chimpanzees to play these word-games. As with watching a circus horse walk on its hind legs, I could not escape the feeling that a species ill-adapted to symbolic communication was struggling with an unnatural task. We are still far from the day when an audience of humans is addressed in the terms of Franz Kafka's chimpanzee: "Honoured Members of the Academy! You have done me the honour of inviting me to give your Academy an account of the life I formerly led as an ape".

John C. Marshall is in the Neuropsychology Unit, part of the Neuroscience Group at the Radcliffe Infirmary, Oxford $O X 26 H E, U K$.

- Two other recent books on ape language Gavagai! Or the Future History of the Animal Language Controversy and Silent Partners: The Legacy of the Ape Language Experiments were reviewed by E. W. Menzel Jr in Nature 323, 497 (1986) 